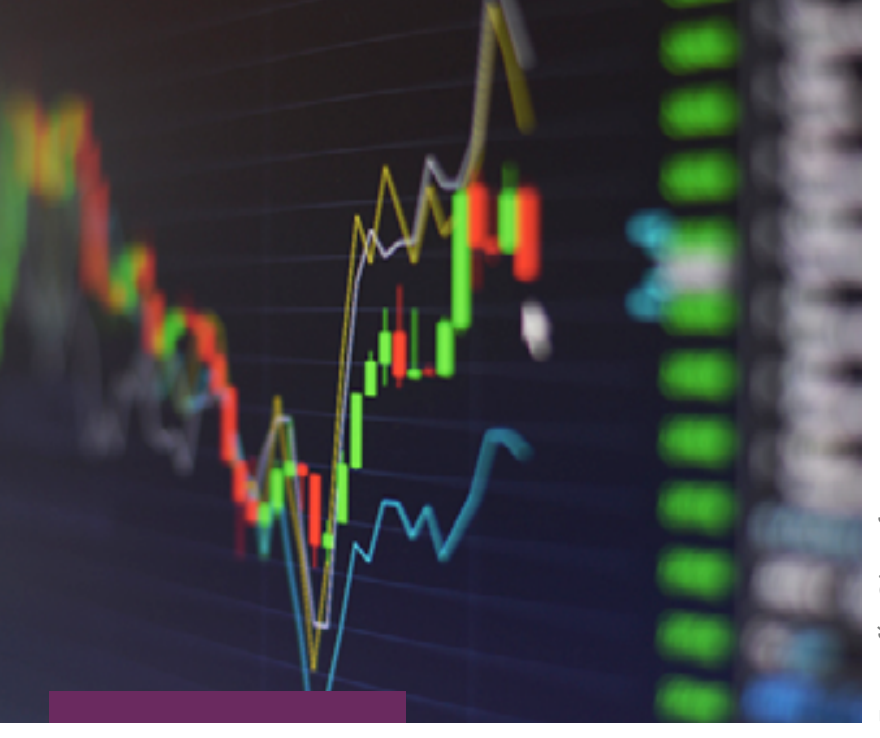

FIGURAS REVISTA ACADÉMICA DE INVESTIGACIÓN

ISSN 2683-2917

Vol. 1, núm. 2, marzo-junio 2020

https://doi.org/10.22201/fesa.figuras.2020.1.2

Esta obra está bajo una licencia

Creative Commons Atribución-NoComercial-

Compartirlgual 4.0 Internacional

\section{Política económica para el crecimiento económico en América Latina en debate}

D Xochitlalli Aroche Reyes

https://doi.org/10.22201/fesa.figuras.2020.1.2.110

Las protestas registradas en algunos países sudamericanos a fines de 2019, así como la migración centroamericana que involucra a México, son un reflejo de procesos económicos sin resolver (aunque en los medios de información se atribuyen las protestas a fallas de la democracia), también son el resultado de la dinámica de la economía mundial y de las políticas económicas instrumentadas en los países latinoamericanos desde hace casi cuatro décadas, a lo largo de las cuales ha predominado en su diseño y aplicación una corriente teórico-doctrinaria que, desde la ortodoxia del Liberalismo económico, considera a los mercados como mecanismos eficientes que pueden prescindir de la gestión económica de las instituciones gubernamentales $\mathrm{y}$, sin tomar en cuenta las particularidades en el desarrollo de cada país, asume que el libre mercado es la única vía para alcanzar el objetivo de la estabilidad de precios, y con ella, automáticamente el crecimiento económico.

\section{Las protestas en América Latina han propiciado un debate académico en la región en torno a temas determinantes de la pobreza y la migración internacional.}

Las mencionadas protestas, visibles ahora, se suman a los indicadores que desde tiempo atrás muestran el lento crecimiento a escala mundial y la profunda desigualdad socioeconómica en los países de América Latina; también señalan las consecuencias de la crisis financiera de 2008. Todo esto ha propiciado un debate académico en esa región que se desarrolla en torno a los efectos adversos de las privatizaciones, la liberalización del comercio y de los movimientos internacionales de capitales que constituyen la globalización económica, sobre el crecimiento económico, la calidad y el nivel de empleo, así como en la distribución del ingreso, todos determinantes de la pobreza y la migración internacional.

En los países desarrollados con economías maduras, el debate generado por la crisis financiera tuvo como objetivo la desregulación de los flujos de capital y la libertad de los grandes bancos internacionales para crear y operar con activos financieros, por ser la causa de una profunda recesión que todavía hoy padece Europa. 
Ante el descontento y las evidencias de que con las reformas económicas neoliberales no se ha cumplido la expectativa de solución a los viejos rezagos -como lo muestran las preocupaciones que dieron nacimiento a los Objetivos del Milenio y a la Agenda 2030 de la ONU-, la desregulación y la libertad de bancos ya mencionadas, cobran relevancia las respuestas contenidas en el conocimiento generado en el ámbito académico desde un marco teórico heterodoxo, cuya perspectiva coloca en el centro el problema del lento crecimiento económico mundial, y se ocupa del bienestar de las personas al buscar explicaciones y estrategias para resolver el elevado desempleo, la precariedad de condiciones de trabajo y aliviar, en parte, la pobreza y la desigual distribución del ingreso.

\section{El proyecto de investigación, iniciativa de Guadalupe Mántey y Teresa S. López, plantea interrogantes sobre la influencia de los procesos monetarios y financieros mundiales sobre la región latinoamericana, así como los alcances y desafíos de las políticas macroeconómicas internas para el logro de un crecimiento sostenido y sostenible.}

Entre las contribuciones reflexivas al debate en América Latina -en oposición a la visión generalizante de la ortodoxia neoliberal- se puede señalar la producción académica generada por un proyecto de investigación coordinado desde la Facultad de Estudios Superiores Acatlán (FEs Acatlán), bajo el Programa de Apoyo a Proyectos de Investigación e Innovación Tecnológica (PAPIIT), de la Dirección General de Asuntos del personal Académico
(DGAPA), de la Universidad Nacional Autónoma de México (UNAM).

\section{El proyecto y sus productos}

La iniciativa de este proyecto fue de Guadalupe Mántey Bastón y Teresa S. López González, académicas con una larga trayectoria en el estudio de los aspectos financieros de la economía internacional. Ellas plantearon interrogantes sobre el curso y la influencia de los procesos monetarios y financieros mundiales sobre la región latinoamericana, así como los alcances y desafíos de las políticas macroeconómicas internas para el logro de un crecimiento sostenido y sostenible. A partir de dichas interrogantes, y de acuerdo con los lineamientos administrativos, el proyecto que nos ocupa -que hasta este momento sigue en curso- ha quedado estructurado a partir de varios subproyectos enumerados a continuación:

\section{1) Coordinación de Políticas para el Desarrollo con} Mercados Globales, IN30010-3, coordinado por Guadalupe Mántey Bastón y Teresa S. López González en colaboración con Carlo Panico, del proyecto Rethinking Finance for Stability and Growth (ReFiSt), del programa Marie Curie Actions.

2) Intervención Esterilizada en los Mercados de Cambios de las Economías Emergentes y su impacto Fiscal. IN 30010-3, coordinado por Guadalupe Mántey Bastón y Teresa S. López González.

3) Riesgos y Oportunidades de Desarrollo en el Actual Marco Institucional de las Relaciones Económicas Internacionales. IN307416, con la coordinación de Teresa S. López González y Luis Ángel Ortiz Palacios.

Las aportaciones que este conjunto de trabajos ha tenido sobre el debate y conocimiento de las particularidades que tiene la economía de América Latina actual, han tomado forma en seminarios anuales donde los profesores investigadores presentan y discuten sus trabajos ante estudiantes de la licenciatura 
y el posgrado de Economía, así como en la publicación de más de veinte artículos, hasta este momento, en cuatro libros colectivos cuyos datos se anotan líneas más adelante.

Cabe mencionar que, desde la perspectiva teórica que guía este proyecto, enriquecida con la discusión y las publicaciones, han sido formados estudiantes de posgrado; algunos de ellos, al egresar, se han incorporado a la docencia e investigación en la propia UNAM y otras universidades. Los libros colectivos, editados en la FEs Acatlán y publicados con el financiamiento de la DGAPA, son los siguientes:

1. La nueva macroeconomía global. Distribución del ingreso, empleo y crecimiento. Coordinado por Guadalupe Mántey B. y Teresa S. López G. 2013.

2. La integración monetaria de América Latina. Una respuesta regional a la inestabilidad global. Coordinado por Guadalupe Mántey B. y Teresa S. López G. 2014.

3. Repensando las finanzas para el crecimiento estable de los países en desarrollo. Coordinado por Guadalupe Mántey, Teresa S. López y Carlo Panico. 2015. 4. Asimetrías económicas y financieras de la globalización. Retos y oportunidades para los países en desarrollo. Coordinado por Teresa S. López y Luis Ángel Ortiz Palacios. 2017.

\section{La contribución al conocimiento sobre la economía de América Latina}

Los trabajos discutidos en los seminarios y publicados en los libros citados obedecen a las interrogantes, surgidas en tres décadas, de un crecimiento económico mundial. Tiempo que corresponde a la mitad del experimentado durante la segunda posguerra y de los efectos negativos sobre el bienestar material de amplios sectores sociales (como resultado del desmantelamiento de la institucionalidad económica construida en la posguerra) cuyas consecuencias podemos apreciar en una deficiente arquitectura financiera internacional, en el desorden monetario y en el exceso de liquidez para financiar las actividades productivas. Todo esto influye sobre el diseño y aplicación de las políticas macroeconómicas -basadas primero en el Monetarismo y, recientemente, en el Nuevo Consenso Macroeconómico-, que están orientadas a procurar la estabilidad de los precios de bienes y servicios, del tipo de cambio y de las tasas de interés con libre movilidad de flujos financieros, que limitan el gasto público.

En el conjunto de artículos que forman parte de este proyecto, los autores han analizado las relaciones causales y los efectos de los procesos señalados, a partir de consideraciones sobre las características particulares de la estructura económica y las monedas de las economías emergentes de América Latina, relacionadas con la economía internacional. Como ya se dijo, desde una perspectiva heterodoxa, contrastan la evidencia empírica con las hipótesis de la teoría dominante, que fueron la base de las políticas macroeconómicas contractivas del gasto público y de la expansión monetaria, junto con la de libre comercio y la cambiaria sin regulación, pero de flotación sucia, es decir, intervenida por los bancos centrales para conservar la estabilidad.

Entre los resultados obtenidos destaca la comprobación de que las expectativas de crecimiento económico y mejora en el bienestar social, contenidas en los supuestos neoliberales, no se cumplen; constatan, por ejemplo, que las políticas para lograr metas de inflación se basan en supuestos que no reflejan la realidad latinoamericana $\mathrm{y}$, al tener como requisito restringir el gasto púbico, frenan el crecimiento económico; por esa razón, se puede concluir que no contribuyen para la acumulación de capital ni con la solución a la baja productividad de los sectores con atraso tecnológico. También demuestran el aumento de importaciones, tanto o más rápido que las exportaciones, cuya competitividad depende de bajos salarios, perpetuando el déficit externo y el estancamiento en capacidades tecnológicas para la producción de bienes y servicios. 
Asimismo, hay artículos con análisis sobre las restricciones que provienen de las tendencias internacionales en el comercio y las finanzas, y que imponen obstáculos al desarrollo económico de los países latinoamericanos, como son: la inestabilidad de los tipos de cambio, la concentración del ingreso y la especialización exportadora de bienes primarios. Todo lo anterior acompañado de la desindustrialización temprana en economías que ya habían alcanzado algún desarrollo en la industria manufacturera. Al respecto, también hay comparaciones con países como Corea del Sur y China, economías que, con políticas alejadas del liberalismo económico, se convirtieron en potencias económicas.

Específicamente, de las finanzas internacionales, destacan dos procesos: 1) La financiarización, caracterizada por el hecho de que el capital financiero obtiene mayores ganancias que el capital invertido en actividades productivas, y por ello no aumenta la inversión necesaria para impulsar el desarrollo tecnológico, la productividad y el empleo en países no desarrollados. A esto se agrega, en las economías emergentes, el endeudamiento del sector público provocado por la entrada de capitales externos de corto plazo; 2) la subordinación de países -como los latinoamericanos- que no poseen monedas de reserva; con implicaciones negativas para su ahorro e inversión a través de mecanismos caracterizados como virtud conflictiva y pecado original.

Con respecto a las estrategias de solución, se propone la coordinación de las políticas macroeconómicas que impulsen el crecimiento. Sobresalen los análisis y propuestas para la cooperación monetaria en la región, cuya importancia radica en que además de ser una posible salida a la reducida disponibilidad de recursos financieros para la inversión productiva, podrían ser un punto de partida para la formulación de planteamientos teóricos alternativos a la teoría convencional.

En suma, el conjunto de autores participantes en este gran proyecto ha aportado un análisis que enri- quece el conocimiento de la situación económica de América Latina y demuestra la necesidad de una visión teórica y de una política económica distinta a la predominante; de un impulso al desarrollo de la estructura económica y la cooperación monetaria, con o sin integración económica, si el objetivo de la política económica es dar respuesta a las demandas sociales de empleo, mejor ingreso personal, así como oportunidades de educación, salud y vivienda.

En este sentido, este proyecto podría ser un detonante para continuar los esfuerzos del Estructuralismo iniciado en los años cincuenta del siglo xx, como herramienta para emancipar y no adaptar a la región latinoamericana, respecto al poder económico que rige la economía internacional.

Por último, el conocimiento generado por un proyecto como el descrito aquí es accesible en la presentación del contexto y los resultados, de modo que puede ser de utilidad a otros especialistas y comunidades de economistas, como contrapeso al sentido común formado por los medios de información a partir de planteamientos teóricos simplificados.

\section{Referencias}

La nueva macroeconomía global. Distribución del ingreso, empleo y crecimiento. Mántey, Guadalupe y Teresa López coordinación. México: DGAPA-FEs Acatlán-UNAM, 2013. La integración monetaria de América Latina. Una respuesta regional a la inestabilidad global. Mántey, Guadalupe y Teresa López coordinación. México: DGAPA-FES Acatlán-UNAM, 2014.

Repensando las finanzas para el crecimiento estable de los países en desarrollo. Mántey, Guadalupe, Teresa López y Carlo Panico coordinación. DGAPA-FEs AcatlánUNAM, 2015.

Asimetrías económicas y financieras de la globalización. Retos y oportunidades para los países en desarrollo. López, Teresa y Luis Ángel Ortiz coordinación. México: DGAPA-FES Acatlán-UNAM, 2017. 